\title{
Karikatürlerle Zenginleştirilmiş Fen Bilimleri Öğretiminin Öğrenci Başarısına ve Tutumuna Etkisi*
}

\author{
Derya KOCAKAVAK ${ }^{* *}$ ve Seçil ERÖKTEN***
}

- Geliş Tarihi:25.02.2020 • Kabul Tarihi: 13.12.2020 • Çevrimiçi Yayın Tarihi: 13.12.2020

\section{$\ddot{\mathbf{O} z}$}

Bu çalışmanın amacı, karikatürlerle zenginleştirilmiş fen bilimleri öğretiminin öğrenci başarısına ve tutumuna etkisini araştırmaktır. Çalışma 2017-2018 eğitim öğretim yılının bahar döneminde Denizli ilinde MEB'e bağlı bir ortaokulda fen bilimleri dersinde 70 deney grubu, 71 kontrol grubu olmak üzere toplam 141 öğrenciden oluşan beşinci sınıf öğrencileri ile haftada dört ders saati olmak üzere toplam 17 hafta sürmüştür. Araştırmanın örneklemini oluşturan deney ve kontrol grupları amaçlı örneklem seçimiyle rastgele olarak belirlenmiştir. Çalışmada ön test-son test kontrol gruplu yarı deneysel desen kullanılmıştır. Araştırmada veri toplama aracı olarak, öğrencilerin bilgilerini ölçmek amacıyla araştırmacı tarafından geliştirilen "Fen Bilimleri Dersi Başarı Testi (FBD Başarı Testi)" ve öğrencilerin fen bilimleri dersine karşı tutumlarını ölçmek amacıyla Keçeci (2014) tarafından geliştirilmiş olan "Fen Bilimleri Dersi Tutum Ölçeği (FBD Tutum Ölçeği)" kullanılmıştır. Ayrıca, işlenilen ünitelerin hedef ve kazanımlarını içeren "Karikatür Destekli Konu Anlatım Sayfaları ve Kavram Karikatürü Çalışma Yaprakları” araştırmacı tarafından hazırlanmıştır. Araştırmada betimsel analiz yapılıp alt problemler doğrultusunda aritmetik ortalama, standart sapma, frekans ve istatiksel analiz kısmında da Mann-Whitney U Testi kullanılmıştır. Yapılan analizler sonucunda karikatürlerle desteklenmiş fen bilimleri öğretiminin öğrencilerin akademik başarılarını arttırdığı ancak fen bilimleri dersine karşı olan tutumlarında anlamlı bir farklılık yaratmadığı belirlenmiştir.

Anahtar sözcükler: karikatür, akademik başarı, tutum

Atıf:

Kocakavak, D. ve Erökten, S. (2021). Karikatürlerle zenginleştirilmiş fen bilimleri öğretiminin öğrenci başarısına ve tutumuna etkisi. Pamukkale Üniversitesi Eğitim Fakültesi Dergisi, 53, 1-20. doi:10. 9779/pauefd.694569.

\footnotetext{
* Bu çalışma birinci yazarın yüksek lisans tezinden üretilmiştir.

** Fen Bilimleri Öğretmeni, Denizli, Türkiye. ORCID: 0000-0003-0164-6818, deryakocakavak@ gmail.com

*** Prof. Dr., Pamukkale Üniversitesi, Eğitim Fakültesi, Fen Bilgisi Eğitimi Anabilim Dalı, Denizli, Türkiye, ORCID: 0000-0002-3149-5267 . erokten@pau.edu.tr
} 


\section{Giriş}

Fen, yaşadığımız dünyayı tanımaya ve anlamamıza yardımcı bir bilim dalıdır. Fen, sadece değişmez gerçeklerden oluşmaz, aynı zamanda düşünmeyi, deneme yanılmayı da temel alan bir bilim dalıdır (MEB, 2006). Fen eğitiminde kalıcılığın ve etkin öğrenmenin sağlanabilmesi için ders işlenişinde daha fazla uyarıcıya yer verilmesi gerektiğine inanılmaktadır. Fen bilimlerindeki soyut kavramların somutlaştırılabilmesinde görsel işitsel araçların önemli bir etkisi bulunmaktadır. Bu sebeple fen bilimleri eğitiminde görsel öğrenme öğretme araçlarına vurgu yapılmıştır (Seçkin Kapucu, 2014,). Görsel unsurlar, okumaya nazaran beyinde daha kolay biçimlendirilmektedir. Görsel unsurlar, öğrencilerin ilgisini ve dikkatinin uzun süreli aktif kalmasına yardımcı olmaktadır. $\mathrm{Bu}$ nedenle görselliğin ön planda olduğu karikatürlerin eğitim öğretim sürecinde kullanılmasının verimi ve kalıcı öğrenmeleri arttıracağını söyleyebiliriz (Örs, 2007). Karikatür kelimesi dilimize Fransızcadan geçmiş olup TDK (2015)'ya göre insan ve yaşadığı toplumla ilgili olan çevre, açlık, yoksulluk, küresel ısınma gibi her türlü konuyu ele alan ve bu konuları abartarak veren, güldüren, aynı zamanda düşündüren resim anlamına gelmektedir. Özer (2007)'e göre karikatür; çizimlerle mizahı birleştiren bir zanaattır. Karikatürler, insan duygu ve düşüncelerin çizim, resim ve sembollerle anlatıldığ 1 görsel bir dildir. Konuyu en yalın halinle sunarken mizahı, abartılı çizimleri işin içine katar (Dalacosta, KamariotakiPaparrigopoulov, Polyvos \& Spyrellis, 2009). Karikatür görseldir, ilgi çekicidir ve tartışma ortamını rahatlıkla başlatabilecek araçlardır. Eğitimde karikatür yalnızca bir görsel iletişim aracı olarak kullanılmaktan öte, mizahi yönüyle de öğrenme-öğretme sürecinde önemli bir yer almaktadır (Ayyıldız, 2010). Özellikle yabancı dil, beşeri bilimler ve fen bilimleri derslerinde karikatür eğitimde iyi bir kaynak olabilecektir (Özer, 2007). Fen bilimleri öğretiminde karikatürün mizahi, yaratıcılık ve ilgi çekicilik gibi özelliklerinden yararlanılarak kavram öğretimi ve bireylerin yaparak yaşayarak öğrenmeleri sağlanabilir. Ayrıca bireylerin düşünme, algılama, fark etme, yorum yapma, eleştirme, eleştirilere açık olabilme ve özeleştiri gibi becerilerinin gelişimine katkı sağlar. Eğitim bilimlerinde kalıcı öğrenmenin en fazla olduğu durumun yaparak yaşayarak katıldığı etkinlikler olduğu bilindiğinden karikatürlerin yorumlanması öğrencilere bırakılarak kalıcı öğrenmeler gerçekleşebilir (Eroğlu, 2010). Eğitimci ve karikatürist, yazar Hakkı Uslu (2007)'ye göre karikatürler öğrencilerin eleştirel ve yaratıcı düşünme becerilerini, mizahi ve estetik bakış açılarını geliştirerek kendilerini ifade etme olanağı sağlarken, yaşadıkları topluma karşı da 
daha duyarlı olmalarına olanak verir. Ayrıca karikatürler ile öğrenciler eğlenirken öğrenirler ve böylece dikkatleri de daha uzun süre aktif kalabilir.

Kavram karikatürleri görsel açıdan sunduğu zenginlik nedeniyle alternatif öğrenmeöğretme yöntemleri arasında bulunmaktadır (Ekici, Ekici ve Aydın, 2007). Kavram karikatürleri diğer karikatür çeşitlerinden farklıdır. Abartı ve mizahi içermezler. Kavram karikatürlerinin çizimler ile olması onların karikatür grubunda olmalarını sağlamaktadır (Uğurel ve Moralı, 2006). Baysarı (2007)'ya göre de kavram karikatürleri mizahi karikatürlerden ayrılmaktadır. Her ne kadar kavram karikatürleri mizahi içerik içerse de yapı olarak çoktan seçmeli soru tarzına benzemektedir. Ancak kavram karikatürlerinde çoktan seçmeli sorulardan farklı olarak konuşma baloncukları ve görsel unsurlar yer almaktadır (Naylor ve Keogh, 1999). Dabell (2008)'e göre kavram karikatürleri öğrencilerde zihinsel çelişkiler yaratarak öğrenme ortamları oluşturur. Kavram karikatürleri sınıf içinde uygulandığında öğrenci karikatürdeki karakteri savunurken aslında kendi fikirlerini açıklama fırsatı bulmaktadır. Öğretmen, kavram karikatürlerini her yaş, yetenek ve düzeydeki öğrenciye rahatlıkla uygulayabilmektedir (Baysarı, 2007). Kavram karikatürlerinin fen bilimleri eğitiminde kullanılma nedenlerini kısaca özetleyecek olursak ise (Balım, İnel, Evrekli ve Kesercioğlu, 2008; Keogh ve Naylor, 1999; Korkmaz, 2004); öğrencilerin araştırmalarını, sorgulamalarını, karşılaştıkları problemlere farklı bakış açıları geliştirebilmelerini, öğrenme sürecinde aktif olabilmelerini, etkili iletişim kurabilmelerini sağlamaktır.

Fen bilimleri eğitiminde bilişsel alan kadar duyuşsal alan da çok önemli yer tutmaktadır (Çepni, 2007). Bireylerin tutumları doğdukları andan itibaren şekillenmeye başlar. $\mathrm{Bu}$ sebeple öğrencilerin erken yaşlarda fen bilimlerine karşı olumlu tutum geliştirmeleri çok önemlidir (Jewett, 1996). Öğrenciler fen bilimleri dersine karşı olumlu ve anlamlı bir tutum geliştirebilmeleri ise öğretmenin 1lımlı yaklaşımına, öğrenciyi yaparakyaşayarak öğrenmeye teşvik etmesi ve öğrencilerin öz yeterlilik seviyesini yükseltmesine bağlıdır (Gökharman Kahraman, 2013). Öğrencilere aldıkları bilgileri yaşantılarıyla ilişkilendirebilecek bir fen eğitimi sunulabilirse, öğrencilerin fen bilimleri dersine yönelik tutum ve davranışlarının artmasına ve hayatlarının her döneminde fen okuryazarı bir birey olarak yetişmesi sağlanabilir (Tatar, 2006). Öğrencilerin fen bilimleri dersine karşı olumlu tutum geliştirmeleri öğrencilerin akademik başarılarını, fen alanına yönelme eğilimlerini ve bilimsel tutum kazanma sürecini etkilemektedir (Altınok,2004). Fen bilimleri öğretmenlerinin kullandıkları yöntem ve tekniklerinin öğrencilerin fen bilimleri dersine karşı 
olumlu bir tutum geliştirme sürecinde çok etkili ve önemli rolü vardır (Göksu, 2012). Bu tekniklerden birisi de karikatürler ve kavram karikatürleridir. Fen bilimleri dersinde karikatür ve kavram karikatürü kullanımının öğrencilerin fen bilimleri dersine karşı olan tutumlarını da olumlu yönde etkileyeceği düşünülmektedir.

Karikatürler öğrenmede etkili bir rol aldığına göre bu çalışmada da çeşitli karikatürler veya kavram karikatürleri kullanılmış ve karikatürlerin öğrencinin başarısına ve tutumuna etkisi incelenmiştir. Buna dayalı olarak araştırmanın alt problemleri aşağıda ifade edilmiştir.

1. "Karikatür destekli öğrenim gören deney grubu öğrencileri ile fen bilimleri öğretim programı doğrultusunda öğrenim gören kontrol grubu öğrencilerinin başarı puanları arasında anlamlı bir fark var mıdır?"

2. “Karikatür destekli öğrenim gören deney grubu öğrencileri ile fen bilimleri öğretim programı doğrultusunda öğrenim gören kontrol grubu öğrencilerinin fen bilimleri dersine yönelik tutumları arasında anlamlı bir fark var mıdır?”

\section{Yöntem}

$\mathrm{Bu}$ araştırmada fen bilimleri dersinde karikatür kullanımının öğrenci başarı ve tutumu üzerine etkisinin incelenmesi amaçlanmıştır. $\mathrm{Bu}$ amaç doğrultusunda araştırma desenlerinden biri olan ön test - son test kontrol gruplu yarı deneysel desen kullanılmıştır. Neden-sonuç ilişkilerini belirlemek istenilen değişkenler için, araştırmacının kontrolünde gözlemi yapılan ve sonucunda verilerin üretildiği modele deneysel desen denir (Karasar, 2009). Ön test-son test kontrol gruplu deneysel desen ise deney ve kontrol gruplarına ön test ve son test uygulanmaktadır. Yarı deneysel desenlerde ise deneysel desenlerden farklı olarak deneklerin seçimi yansız olmamaktadır (Balcı, 2001). Bu modele göre biri deney biri kontrol grubu olmak üzere önceden oluşturulmuş olan şubelerden rastgele dört şube seçilmiştir. Her iki grup öğrencilerine araştırma öncesi ve sonrasında aynı testler uygulanmıştır. Araştırmada kullanılan araştırma deseni Tablo 1'de özetlenmiştir. 
Tablo 1. Araştırmanin Deseni

\begin{tabular}{llll}
\hline Grubun Adı & İşlem Öncesi & İşlemler & İşlem Sonrası \\
\hline Deney & FBD Başarı & Karikatür destekli öğretim & FBD Başarı Testi \\
Grubu & Testi FBD & & FBD Tutum \\
& Tutum Ölçeği & & Ölçeği \\
Kontrol & & Mevcut öğretim programında & \\
Grubu & & var olan öğretim yöntemleri & \\
\hline
\end{tabular}

\section{Çalışma Grubu (Katılımcılar)}

Çalışma grubunu 2017-2018 eğitim ve öğretim yılı bahar döneminde Denizli ilinde MEB’e bağlı bir ortaokulda öğrenim gören 5. sınıf öğrencileri oluşturmaktadır. Araştırma grubunda 68 erkek, 73 kız öğrenci olmak üzere toplam 141 öğrenci yer almaktadır. Araştırmada iki şube deney grubu, iki şube kontrol grubu olarak amaçlı örneklem seçimiyle rastgele belirlenmiştir. Araştırma grubuna ilişkin bilgiler Tablo 2'de verilmiştir.

Tablo 2. Araştırma Grubu Özellikleri

\begin{tabular}{llll}
\hline & K1z Öğrenci Sayısı & Erkek Öğrenci Sayısı & Toplam \\
\hline Deney Grubu & 40 & 30 & 70 \\
Kontrol Grubu & 33 & 38 & 71 \\
\hline
\end{tabular}

\section{Çalışmada Kullanılan Ölçme (Veri Toplama) Araçları}

\section{Fen Bilimleri Dersi Başarı Testi (FBD Başarı Testi)}

Araştırmacı tarafından geliştirilen FBD Başarı Testi'nde; boşluk doldurma, doğru - yanlış, kısa cevaplı sorular ve çoktan seçmeli soruları içeren 32 madde bulunmaktadır. FBD Başarı Testi hazırlanırken 5. sınıf fen bilimleri ders kitabı ve ilgili alan yazınlar incelenmiş ve konu alanları ile ilgili kazanımlar belirlenmiştir. Bu kazanımlara yönelik sorular hazırlanmıştır. Hazırlanan FBD Başarı Testi biri Fen Bilgisi eğitiminde uzman, ikisi Fen Bilimleri öğretmeni biri de Türkçe öğretmeni olmak üzere dört uzmanın görüşleri alınıp gerekli düzenlemelerden sonra pilot çalışması yapılmıştır. Pilot çalışma, Fen öğretimi programının değişmesinden dolayı konuları daha önce öğrenmiş olan Denizli ilinde MEB'e bağlı bir 
ortaokulda 7. sınıfta öğrenim gören 100 öğrenciyle gerçekleştirilmiştir. Pilot uygulamadan sonra her bir maddenin ayırt edicilik ve güçlük indeksleri ayrı ayrı hesaplanmış ve analizler sonucu son düzenlemeler yapılmıştır. FBD Başarı Testinin KR20 güvenirlik katsayısı 0,93 olarak hesaplanmıştır. Bulunan bu değer ise FBD Başarı Testinin güvenilir bir test olduğunu göstermektedir. Hazırlanan FBD Başarı Testi deney ve kontrol grubundaki öğrencilere hem ön test hem de son test olarak uygulanmıştır.

\section{Fen Bilimleri Dersi Tutum Ölçeği (FBD Tutum Ölçeği)}

Araştırmada Keçeci (2014) tarafından geliştirilen FBD Tutum Ölçeği kullanılmıştır. Fen bilimleri dersine karşı öğrencilerin tutumunu ölçen bu ölçeğin Cronbach Alfa güvenilirlik katsayısı ölçeğin geliştiricisi tarafından 0,90 olarak hesaplanmıştır. Araştırmada kullanılan FBD Tutum Ölçeği beşli likert tipi ölçektir. Ölçekte yer alan ifadelerin bir kısmı olumlu (20 tanesi), bir kısmı ise olumsuz (11 tanesi) ifadeleri içermektedir. Ölçek 31 maddeden ve üç faktörden oluşmaktadır. Bu faktörlerin fen bilimleri dersini sevme, fen bilimleri dersine karşı duyulan merak ve fen bilimleri dersinin günlük hayatla ilişkilendirmesi olarak ölçek geliştiricisi tarafından gruplandırılmıştır. Ölçek deney ve kontrol grubu öğrencilerine hem ön test hem de son test olarak uygulanmıştır.

\section{Karikatür Destekli Konu Anlatım Kâğıtları ve Kavram Karikatürü Çalışma Yaprakları}

Çalışmada uygulama aracı olarak kullanılacak karikatür destekli konu anlatım kâğıtları ve kavram karikatürü çalışma yaprakları hazırlanmadan önce 5. Sınıf fen bilimleri dersi müfredatında yer alan kazanımlar tespit edilmiştir. Bu kazanımlar dikkate alınarak 48 tane karikatür destekli konu anlatım kağıtları ve kavram karikatürü çalışma yaprakları hazırlanmıştır. Karikatür destekli konu anlatım kâğıtları hazırlanırken her ünitede çizgi film karakterleri ve aralarında geçen diyaloglar ile öğrencilerin eğlenerek ve keşfederek konuyu anlamaları sağlanmaya çalışılmıştır. Kavram karikatürü çalışma yaprakları hazırlanırken de diyalogların kısa ve öz olmasına, bilimsel fikirleri içermesine, diyaloglarda kavram yanılgılarına da yer verilmesine ve yine diyaloglarda alternatif düşüncelerin yer almasına dikkat edilmiştir. Kavram karikatürü çalışma yaprakları hazırlanırken çizgi film karakterlerinden yararlanılmıştır. Araştırmacı tarafından oluşturulan karikatürlerinin geçerliliği konusunda fen bilimleri alanında uzman bir öğretim üyesi ve 5 Fen Bilimleri öğretmeni, 1 Türkçe öğretmeni, 1 Görsel Sanatlar öğretmeni tarafından kontrol edilmiştir. Görüşler doğrultusunda karikatürler üzerinde düzeltmeler yapılmıştır. 


\section{İşlem}

Araştırma 5. sınıfta öğrenim gören 141 öğrenci ile haftada dört ders saati olmak üzere toplam 68 ders saati boyunca sürdürülmüştür. Toplam 17 hafta süren araştırmada 5 . sınıf Madde ve Değişim, Işı̆̆ın Yayılması, İnsan ve Çevre ile Elektrik Devre Elemanları ünite konularını içeren 20 kazanım dikkate alınmıştır. Her iki grupta da dersler araştırmacı tarafından işlenmiştir. Uygulamaya başlamadan FBD Başarı Testi ve FBD Tutum Ölçeği ön test olarak uygulanmıştır.

Çalışmada kontrol grubunda 5. Sınıf Fen Bilimleri Öğretim Programı doğrultusunda dersler işlenmiştir. Derslerin işlenişi sırasında öğrenci ders kitabı kullanımı ağırlık kazanmıştır. Gerektiğinde soru cevap yönteminden ve Eğitim Bilişim Ağın'dan (EBA) konu ile ilgili bulunan videolardan destek alınmıştır. Ayrıca öğrenci ders kitabında bulunan etkinliklerle dersler pekiştirilmiştir.

Çalışmada deney grubunda 5. sınıf Fen Bilimleri Öğretim Programı doğrultusunda dersler işlenirken karikatürler ile dersler desteklenmiştir. Araştırmacı tarafından tüm kazanımlar için hazırlanan 48 tane karikatür destekli konu anlatım ve çalışma yaprakları hazırlanmıştır. Araştırmacı tarafından oluşturulan karikatürler deney grubundaki öğrencilere tek tek dağıtılmış aynı zamanda da karikatürler akıllı tahta sayesinde de sınıfa gösterilmiştir. Karikatürler öğrenciler tarafından okunarak, üzerlerinde konuşulmuş ve bilgilere öğrencilerin ulaşması sağlanmıştır. $\mathrm{Bu}$ süreçte araştırmacı yani öğretmen öğrencilere rehberlik etmiştir. Çalışma yaprağı biçiminde hazırlanılan kavram karikatürlerinde de dersin başında öğrencilerin ön bilgilerini ve kavram yanılgılarını tespit etmek amacıyla çalışma yapraklarının öğrenciler tarafından cevaplandırılması istenmiştir. Diğer karikatürlerin de öğrenciler tarafından incelenmesinden sonra çalışma yaprağındaki sorulara kimin ne cevap verdiği sorulup konu ile ilgili fikirleri alınmış ve sınıfta tartışma ortamı yaratılmıştır. Yanlış cevapların neden yanlış olduğu tartışma sonucunda ortak kararlarla öğrenciler tarafindan açıklanmış ve yine ortak kararlar doğrultusunda öğrencilerin doğru cevaba ulaşması sağlanmıştır. Ders bitiminde dağıtılan karikatürleri defterlerine yapıştırarak öğrencilerin ders ile ilgili gerekli notları almaları sağlanmıştır.

Uygulama sonrasında FBD Başarı Testi ve FBD Tutum Ölçeği son test olarak tekrar uygulanmıştır. 


\section{Veri Analizi}

Araştırmada kullanılan 32 sorudan oluşan FBD Başarı Testinde her doğru cevap için 1, her yanlış cevap için 0 puanda değer verilmiştir. Testten en az 0 en fazla 32 puan alınabilmektedir. FBD Başarı Testini çalışma grubumuza uyguladığımızda KR20 güvenirlik katsayısı 0,634 olarak hesaplanmıştır. Araştırmada Shapiro-Wilk testi sonucunda anlamlılık değeri $\mathrm{p}<0.05$ olduğu için verilerin normal dağılım göstermediği görülmüştür. Bu nedenle parametrik olmayan (nonparametrik) analizlerin yapılmasına karar verilmiştir. Bağımsız iki grup olan deney grubu ve kontrol grubunun başarı puanları arasındaki anlamlılık farkını karşılaştırabilmek için ise Mann-Whitney U Testi kullanılmıştır.

Araştırmada fen bilimleri dersine karşı öğrencilerin tutumunu ölçen Keçeci (2014) tarafından geliştirilen FBD Tutum Ölçek'inden en az 31 en fazla 155 puan alınabilmektedir. Ölçekten alınan yüksek puanlar olumlu tutumu göstermektedir. FBD Tutum Ölçeği'ni çalışma grubumuza uyguladığımızda Croanbach Alfa güvenilirlik katsayısı 0,683 olarak hesaplanmıştır. Araştırmada Shapiro-Wilk testi sonucunda anlamlılık değeri $p<0.05$ olduğu için verilerin normal dağılım göstermediği görülmüştür. Bu nedenle parametrik olmayan (nonparametrik) analizlerin yapılmasına karar verilmiştir. Bağımsız iki grup olan deney grubu ve kontrol grubunun tutum puanları arasındaki anlamlılık farkını karşılaştırabilmek için ise Mann-Whitney U Testi kullanılmıştır.

\section{Bulgular}

Deney ve kontrol grubunun uygulama öncesinde ve uygulama sonrasında Fen Bilimleri Dersi Başarı Testi ve Fen Bilimleri Dersi Tutum Ölçeği’nin aritmetik ortalamaları ve standart sapma değerleri Tablo 3'de verilmiştir.

Tablo 3. Uygulanan Başarı Testi ve Tutum Ölçeği Puanlarının Aritmetik Ortalamaları ve Standart Sapma Dĕ̌gerleri

\begin{tabular}{|c|c|c|c|c|c|c|c|c|c|}
\hline & & \multicolumn{4}{|c|}{ Başarı Testi } & \multicolumn{4}{|c|}{ Tutum Ölçeği } \\
\hline & & \multicolumn{2}{|c|}{ Öntest } & \multicolumn{2}{|c|}{ Sontest } & \multicolumn{2}{|c|}{ Öntest } & \multicolumn{2}{|c|}{ Sontest } \\
\hline & $\mathrm{N}$ & $X$ & Ss & $X$ & Ss & $X$ & Ss & $X$ & Ss \\
\hline Deney Grubu & 70 & 7,25 & 2,47 & 29,61 & 1,91 & 81,27 & 8,86 & 81,38 & 6,89 \\
\hline Kontrol Grubu & 71 & 7,07 & 3,71 & 25,76 & 3,82 & 84,04 & 9,03 & 82,76 & 11,63 \\
\hline
\end{tabular}


Tablo 3 incelendiğinde uygulama öncesinde deney grubu öğrencilerinin başarı testine ait aritmetik ortalama puanları $\mathrm{X}=7,25$ iken, uygulama sonrasında aritmetik ortalamanın $X=29,61$ 'e yükseldiği görülmektedir. Deney grubu öğrencilerinin tutum ölçeği öntest puanları incelendiğinde aritmetik ortalamanın $\mathrm{X}=81,27$ iken, uygulama sonrası aritmetik ortalamanın $X=81,38$ 'e yükseldiği görülmektedir. Kontrol grubu öğrencilerinin başarı testi öntest puanları incelendiğinde aritmetik ortalamalarının $X=7,07$ iken, uygulama sonrasında aritmetik ortalamanın $X=25,76$ 'ya yükseldiği görülmektedir. Kontrol grubu öğrencilerinin tutum ölçeği öntest başarı puanları incelendiğinde aritmetik ortalama $X=84,04$ iken, uygulama sonrası aritmetik ortalamanın $X=82,76$ 'ya düştüğü görülmektedir.

Deney grubu ve kontrol grubu öğrencilerinin uygulama öncesinde başarı testi puanlarının analizi Mann-Whitney U Testi ile yapılmış ve sonuçlar Tablo 4'de gösterilmiştir.

Tablo 4. Deney ve Kontrol Grubu Öğrencilerinin Başarı Testi Ön Test Puanlarının Karşılaştırılması

\begin{tabular}{lllllll}
\hline Grup & N & Sira Ortalamas1 & Sira Toplamı & U & z & p \\
\hline Deney Grubu & 70 & 72,51 & 5075,5 & & & \\
Kontrol Grubu & 71 & 69,51 & 4935,5 & 2379,5 & $-0,438$ & 0,662 \\
& & & & & \\
\hline
\end{tabular}

Tablo 4'den elde edilen Mann-Whitney U Testi sonuçlarına göre deney grubu öğrencilerinin ön test başarı puanları ile kontrol grubu öğrencilerinin ön test başarı puanları arasında istatiksel olarak anlamlı bir fark tespit edilmemiştir $(U=2379,5 ; p>0,05)$. Elde edilen sonuçlara göre deney ve kontrol grubu öğrencilerinin uygulama öncesinde başarı seviyelerinin eşit olduğu söylenebilir.

Deney grubu ve kontrol grubu öğrencilerinin uygulama öncesinde tutum puanlarının analizi Mann-Whitney U Testi ile yapılmış ve sonuçlar Tablo 5’te gösterilmiştir.

Tablo 5'ten elde edilen Man-Whitney U Testi sonuçlarına göre deney grubu öğrencilerinin ön test tutum ölçeği puanları ile kontrol grubu öğrencilerinin ön test tutum ölçeği puanları arasında istatiksel olarak anlamlı bir fark tespit edilmemiştir ( $U=2030$; p>0,05). Elde edilen sonuçlara göre deney ve kontrol grubu öğrencilerinin uygulama öncesinde fen bilimleri dersine karşı olan tutumlarının eşit olduğu söylenebilir. 
Tablo 5. Deney ve Kontrol Grubu Ögrrencilerinin Tutum Ölçeği Ön Test Puanlarının Karşılaştırılması

\begin{tabular}{lllllll}
\hline Grup & N & Sira Ortalamasi & Sira Toplamı & U & z & p \\
\hline Deney Grubu & 70 & 64,5 & 5496 & & & \\
Kontrol Grubu & 71 & 77,41 & 4515 & 2030 & $-1,879$ & 0,60 \\
\hline
\end{tabular}

Araştırmanın ilk alt problemi olan "Karikatür destekli öğrenim gören deney grubu öğrencileri ile fen bilimleri öğretim programı doğrultusunda öğrenim gören kontrol grubunun öğrencilerinin başarı puanları arasında anlamlı bir fark var mıdır?” sorusuna cevap bulmak için yapılan Mann-Whitney U Testi'ne ait sonuçlar Tablo 6'da sunulmuştur.

Tablo 6. Deney ve Kontrol Grubu Öğrencilerinin Son Test Başarl Puanlarının Karşılaştırılması

\begin{tabular}{lllllll}
\hline Grup & N & Sira Ortalamas & Sira Toplamı & U & Z & p \\
\hline Deney Grubu & 70 & 94,89 & 6642 & & & \\
Kontrol Grubu & 71 & 47,45 & 3369 & 813 & $-6,934$ & 0,00 \\
\hline
\end{tabular}

Tablo 6'dan elde edilen Mann-Whitney U Testi sonuçlarına göre deney grubu öğrencilerinin başarı puanları ile kontrol grubu öğrencilerinin başarı puanları arasında istatiksel olarak deney grubu lehine anlamlı bir fark olduğu tespit edilmiştir (U=813; $\mathrm{p}<0,05)$. Elde edilen sonuçlara göre karikatür destekli fen öğretiminin yapıldığı öğrencilerin akademik başarılarında daha fazla artış olduğu gözlemlenmiştir.

Araştırmanın ikinci alt problemi olan "Karikatür destekli öğrenim gören deney grubu öğrencileri ile fen bilimleri öğretim programı doğrultusunda öğrenim gören kontrol grubunun öğrencilerinin fen bilimleri dersine yönelik tutumları arasında anlamlı bir fark var mıdır? sorusuna cevap bulmak için yapılan Mann-Whitney U Testi'ne ait sonuçlar Tablo 7'de sunulmuştur.

Tablo 7'den elde edilen Mann-Whitney U Testi sonuçlarına göre deney grubu öğrencilerinin tutum ölçeği puanları ile kontrol grubu öğrencilerinin tutum ölçeği puanları arasında istatiksel olarak anlamlı bir fark tespit edilmemiştir $(U=2225,5 ; p>0,05)$. Karikatür destekli yapılan öğretiminin öğrencilerin fen bilimleri dersine karşı olan tutumlarında anlamlı bir fark yaratmadığı görülmektedir. 
Tablo 7. Deney ve Kontrol Grubu Öğrencilerinin Son Test Tutum Puanların Karşılaştırılması

\begin{tabular}{lllllll}
\hline Grup & N & Sira Ortalamas & Sira Toplamı & U & z & p \\
\hline Deney Grubu & 70 & 67,29 & 4710,5 & & & \\
Kontrol Grubu & 71 & 74,65 & 5300,5 & 2225,5 & $-1,071$ & 0,284 \\
\hline
\end{tabular}

\section{Tartışma}

Günümüz eğitim sisteminde yapılandırmacı yaklaşımda sorgulayan, araştıran ve çözüm üretebilen bireyler yetiştirilmesi amaçlanmaktadır. Yapılandırmacı eğitim yaklaşımında birçok alternatif öğretim yöntemleri kullanılabilmektedir. Karikatürle eğitim bunlardan biridir. Karikatürle eğitim öğrencilerin derse ilgisini arttırmakta ve dersleri eğlenceli hale getirmektedir. Ayrıca karikatürle eğitimde öğrenci sorgulayan, araştıran ve çözüm üretebilen bireyler haline gelebilmektedir. Bu çalışmada (MEB) 2017 yılı Fen Bilimleri Programındaki beşinci sınıf kazanımlarına uygun olarak hazırlanmış karikatür destekli fen eğitiminin öğrencilerin akademik başarı puanları ve fen bilimleri dersine karşı olan tutumları ölçülmüş ve analizleri yapılmıştır.

Araştırmanın birinci alt probleminde deney ve kontrol grubu öğrencilerinin fen bilimleri dersi başarı puanları arasındaki farklılık incelenmiştir. Araştırmadan elde edilen bulgulara göre uygulanan başarı testinin deney ve kontrol grubunun ön test puanları arasında anlamlı bir farklılık bulunmamıştır. Bu durumda uygulama öncesi her iki grubun başarı seviyelerinin eşit olduğunu söyleyebiliriz. Öte yandan son test başarı puanlarında deney grubu lehine anlamlı bir farklılık bulunmuştur. Bu durum yapılan karikatür destekli fen eğitiminin beşinci sınıf öğrencilerinin akademik başarılarının artmasında etkili olduğunu göstermektedir. $\mathrm{Bu}$ durumun temel sebebinin karikatür destekli fen eğitiminin sınıf içi tartışmaya olanak sağlayarak öğrencilerin derse daha aktif katılımını sağlaması olduğu düşünülmektedir. Deney grubundaki öğrenciler doğru bilgiye tartışma ortamında deneme yanılma yoluyla ulaşma şansı bulmuşlardır. Öğrenciler tartışma sürecinde eleştirel düşünüp problem çözmek için o zamana kadar edindikleri bilimsel bilgileri sentezleyerek kullanabilmişlerdir. Ayrıca karikatürler yardımıyla deney grubundaki öğrenciler bilgiyi günlük hayata daha çok uyarlayabilmişlerdir. Ancak kontrol grubu öğrencileri sadece ders kitaplarındaki etkinliklerin sonucunu gözlemleyerek sonuç odaklı bilgiye ulaşmışlardır. 
Dolayısıyla kontrol grubundaki öğrencilerinin eleştirel düşünme konusunda daha pasif oldukları düşünülmektedir. Karikatür destekli eğitimde eleştirel düşünme ile öğrenmeleri pekişen öğrenciler daha başarılı olmuştur. Karikatür destekli fen eğitiminin uygulandığı deney grubundaki öğrencilerin akademik olarak daha başarılı olmalarındaki bir diğer etkenin de karikatürlerin mizahi ve görsel yönden zenginliği olduğu düşünülmektedir. Örs (2007)’e göre dikkat çeken görsel unsurlar öğrencinin daha çok ilgisini çekmekte ve kalıcı öğrenmeyi kolaylaştırmaktadır. Deney grubunda kullanılan karikatürlerin de görsel ve mizahi yönünden yararlanılarak eğitimin daha ilgi çekici hale gelmesi akademik başarının artmasında önemli bir etken olmuştur.

Alan yazın incelendiğinde mevcut çalışmada elde edilen bulgulara paralel olarak karikatür destekli fen eğitiminde öğrencilerin akademik başarılarının olumlu yönde etkilendiği sonucuna ulaşan çalışmalar mevcuttur Dalacosto, Kamariotaki-Paparrigopoulov, Palyvos ve Spyrellis (2009), Evrekli (2010); Eroğlu (2010), Chin ve Teou (2010), Gölgeli ve Saraçoğlu, (2011), Gölgeli, (2012), Çetin (2012), Taş (2013), Demirci (2013), Yolcu (2013), Yılmaz (2013), Taşkın (2014), Yİn Yin, Wai Bing, Yusof ve Zakariya (2016), Ayhan (2017) ortaokul öğrencileri ile yaptıkları çalışmalarda karikatür kullanımının fen bilimleri dersindeki akademik başarıyı olumlu yönde arttırdığı sonucuna ulaşmışlardır. Akengin ve İbrahimoğlu (2010), Yaman (2010), Akkaya (2011), Tokcan ve Alkan (2013), Topçubaşı ve Polat (2014) çeşitli branşlarda ortaokul öğrencileri ile yaptıkları çalışmalarda derslerinde karikatür kullanımının öğrenci başarısını arttırdığı sonucuna ulaşmışlardır. Özün Kılıç (2010) ve Young ve Kee (2017) yıllarında ilkokul öğrencileri ile yaptıkları çalışmalarda derslerde karikatür kullanımının öğrenci başarısını arttırdığı sonucuna ulaşmışlardır. Ayyıldız (2010) ve Köse Özay (2013) lise öğrencileri ile yaptıkları çalışmalarda derslerde karikatür kullanımı ile öğrencilerin akademik başarıları arasında olumlu yönde bir anlamlı fark olduğunu gözlemlemişlerdir Keogh ve Naylor (1999); Köklükaya, Yıldırım Güven ve Selvi (2016), Steininger (20139 ve İnan ve Kaya (2017) yıllarında öğretmen ve öğretmen adayları ile çeşitli branşlar üzerinde yaptıkları çalışmalarda da karikatür kullanımının başarıyı arttırdığı yönde sonuçlara ulaştıklarını görmekteyiz. Ayhan (2017) çalışmasında kavram karikatürü kullanımının altıncı sınıf öğrencilerinin kuvvet ve hareket ünitesindeki başarı düzeyi üzerindeki etkilerini incelemiştir. Çalışmada çoktan seçmeli sorulardan oluşan ön test-son test gruplara uygulanmıştır. Çalışma sonucunda kavram karikatürleriyle derslerin işlendiği deney grubu lehine başarı puanlarında anlamlı bir farklılık bulunmuştur. Dalacosta, Kamariotaki-Paparrigopoulov, Palyvos ve Spyrellis (2009) çalışmalarında animasyon 
destekli karikatür kullanımının ilköğretim öğrencilerinin bilimsel konuları öğrenmeleri üzerindeki etkisini tespit etmeyi ve değerlendirmeyi hedeflemişlerdir. Toplam 179 öğrenciyle gerçekleşen çalışmanın sonucunda karikatür kullanımının öğrencilerin kavram yanılgılarının çok olduğu kavramlarda dahi öğrenmenin arttığı sonucuna ulaşmışlardır. Akademik başarı yönünden farklı sonuçlara ulaşılan çalışmalar da bulunmaktadır. Örneğin Göksu (2012) yaptığı tez çalışmasında kavram karikatürü kullanımının deney ve kontrol grubunun son test başarı puanları arasında anlamlı bir fark yaratmadığg sonucuna ulaşmıştır.

Araştırmanın ikinci alt probleminde deney ve kontrol grubu öğrencilerinin fen bilimleri dersine karşı tutum puanları arasındaki farklılık incelenmiştir. Elde edilen bulgulardan deney ve kontrol grubunun son test tutum puanları arasında anlamlı bir farklılık bulunamamıştır. Bireylerin tutum sahibi olabilmeleri yaşantıları ile kısıtlıdır. Ayrıca bireyin bir olay ya da kavramla ilgili tutum geliştirebilmesi için bunlar hakkında zihin haritasına sahip olması gerekir (Gökharman Kahraman, 2013). Açıklamaya göre de uygulama öncesi deney ve kontrol grubunun tutum puanları arasında anlamlı bir farklılığın olmaması beklenen bir durumdur. Araştırma sonrasında deney ve kontrol grubunun son test tutum puanları arasında da anlamlı bir farklılık olmadığı bulunmuştur. Karikatür destekli fen eğitiminin tutumlar üzerinde anlamlı bir farklılık oluşturamamasının nedeninin öncelikli olarak tutumların belirli bir süreç içerisinde oluşmasından kaynaklandığını söyleyebiliriz. Ayrıca tutumların değişiminin zor olduğu, değişim gerçekleşse bile davranışsal ya da duyuşsal bileşenlerinde hemen gözlenememesinin bir diğer etken olduğu düşünülmektedir. Karasar (2009)'ın, bireylere has tutumlarının kolay kolay değişmeyeceği ifadesi de bu düşünceyi desteklemektedir.

Alan yazın incelendiğinde mevcut çalışmada elde edilen bulgulara paralel olarak karikatür destekli fen eğitiminin öğrencilerin tutumu üzerinde anlamlı bir farklılık yaratmadığı sonucuna ulaşan çalışmalar mevcuttur (Baysarı2007; Evrekli, İnel ve Balım 2011; Çiçek, 2011; Gölgeli, 2012; Yılmaz, 2013). Bazı araştırmalar ise tutum yönünden farklı sonuçlara ulaşmışlardır. Örneğin Meriç (2014) tez çalışmasında kavram karikatürü kullanımının öğrenci tutumu üzerindeki etkisini araştırmıştır. Çalışması sonucunda kavram karikatürü kullandığı deney grubundaki son test tutum puanlarının anlamlı fark yarattığını gözlemlemiştir.

\section{Sonuç}

Karikatür zenginleştirilmiş fen bilimleri uygulamasının öğrenciler üzerindeki etkisini tespit edebilmek için yapılan başarı testi ve tutum ölçeği sonuçlarına göre karikatürlerle 
zenginleştirilmiş fen bilimleri öğretiminin dersin daha iyi anlaşılmasını ve daha kalıcı öğrenmenin gerçekleştirebildiği ancak derse karşı olan tutumda anlamlı bir farklılık yaratmadığı söylenebilir. Bu araştırmanın sonucunda da karikatür destekli fen öğretiminin öğrenci başarısını arttırmada literatürde yer alan araştırma sonuçlarına paralel olarak öğrencilerin fen bilimleri dersi başarılarını olumlu yönde etkileri olduğu söylenebilir. Yine bu araştırmanın sonucunda da karikatür destekli fen öğretiminin öğrenci tutumunu arttırmada literatürde yer alan bazı araştırma sonuçlarına paralel olarak bir etkisi olmadığı söylenebilir.

Çalışmanın bu bölümünde araştırmanın sınırlılıkları dikkate alınarak araştırmacı tarafından şu önerilerde bulunulmuştur.

1. Araştırma beşinci sınıf öğrencileriyle gerçekleştirilmiştir. Farklı sınıf seviyeleri ile de karikatür destekli fen eğitimi uygulamaları yapılabilir.

2. Araştırmada karikatür destekli fen eğitimi 17 hafta ile sınırlı kalmıştır. Yapılacak çalışmalarda uygulama süresi dikkate alınmalıdır.

3. Fen bilimleri dersi dışında farklı disiplinlerde de karikatür destekli eğitim kullanılabilir.

4. Karikatür destekli eğitimlerde öğrencilerin ilgisini çekebilecek, merak duygusunu uyandırabilecek ve sorgulamaya yönlendirebilecek günlük hayatla bağlantılı olan konular derse giriş etkinlikleri olarak kullanılabilir.

5. Bu araştırmada karikatür destekli eğitim Madde ve Değişim, Işığın Yayılması, İnsan ve Çevre ile Elektrik Devre Elemanları konuları ile kısıtlı kalmıştır. Farklı fen bilimleri konularında da uygulamalar yapılabilir.

6. Karikatür destekli etkinliklerde öğretmenlerin ve öğrencilerin rollerini belirleyen yönergeler kullanılarak öğretim sürecinin daha etkili ve verimli kullanılması sağlanabilir.

7. Karikatür destekli öğretim sürecindeki uygulamalar için öğretmen adaylarının tecrübe kazanmaları sağlanmalıdır.

8. Karikatür destekli öğretim sürecinde öğrencilerin farklı bakış açılarını görmeleri, daha çok fikir üretip sürece daha fazla katılabilmeleri için küçük gruplar halinde tartışmalar dikkate alınmalıdır.

9. Teknoloji desteğiyle bu karikatürler etkileşimli hale getirilebilir. 
Etik Kurul İzin Bilgisi: Bu araştırma, birinci yazarın yüksel lisans tezinden üretilmiştir.

Yazar Çıkar Çatışması Bilgisi: Herhangi bir çıkar çatışması bulunmamaktadır.

\section{Yazar Katkısı:}

Birinci yazar, teorik çerçevenin oluşturulması, veri analizi, bulgular, sonuç ve tartışma kısmında katkı sağlamıştır. İkinci yazar, teorik çerçevenin oluşturulması, bulgular, sonuç ve tartışma, öneriler kısmında katkı sağlamıştır. 


\section{Kaynakça}

Akengin, H. ve İbrahimoğlu, Z. (2010). Sosyal bilgiler dersinde karikatür kullanımının öğrencilerin akademik başarısına ve derse ilişkin görüşlerine etkisi. Ondokuz Mayıs Üniversitesi Eğitim Fakültesi Dergisi, 29(2), 1-19.

Akkaya, A. (2011). Karikatürlerle dil bilgisi öğretimi. Selçuk Üniversitesi Eğitim Bilimleri Enstitüsü, Konya.

Altınok, H. (2004). İşbirlikli Öğrenme, Kavram Haritalama, Fen Başarısı, Strateji Kullanımı ve Tutum. Dokuz Eylül Üniversitesi Eğitim Bilimleri Enstitüsü, İzmir.

Ayhan, H. (2017). Ortaokul 6. sinıf kuvvet ve hareket ünitesinde kullanılan kavram karikatürlerinin öğrencilerin akademik başarılarına ve fen öğrenmeye yönelik motivasyonlarına etkisi. Gazi Üniversitesi Eğitim Bilimleri Enstitüsü, Ankara.

Ayyıldız, N. (2010). Coğrafya öğretiminde karikatür materyali kullanımının öğrenci başarısına etkisi. Marmara Üniversitesi Eğitim Bilimleri Enstitüsü, İstanbul.

Balc1, A. (2001). Sosyal bilimlerde araştırma yöntem, teknik ve ilkeler. Ankara: PegamA Yayınc1lik

Balım, A., İnel, D., Evrekli, E. ve Kesercioğlu, T. (2008). The use of concept cartoons in constructive science and technology education: "The examples about the subject of presssure”. XIII. IOSTE Symposium, The Use of Science and Technology Education for Peace and Sustainable Development, Kuşadasi/Turkey.

Baysar1, E. (2007). Illköğretim düzeyinde 5. sinıf fen ve teknoloji dersi canlılar ve hayat ünitesi ögrretiminde kavram karikatürü kullanımının öğrenci başarısına, fen tutumuna ve kavram yanılgılarının giderilmesine olan etkisi. Dokuz Eylül Üniversitesi Eğitim Bilimleri Enstitüsü, İzmir.

Chin, C. \& Teou, L-Y. (2009). Using concept cartoons in formative assessment: Scaffolding students' argumentation. International Journal of Science Education. 31(10), 13071332

Çepni, S. (Ed.) (2007). Kuramdan uygulamaya fen ve teknoloji ögrretimi. Ankara: PegamA Yayıncilık.

Çetin, E. (2012). Karikatürler ile zenginleştirilmiş fen ve teknoloji dersinin öğrenci başarısı ve tutumları üzerine etkisi. Selçuk Üniversitesi Eğitim Bilimleri Enstitüsü, Konya. 
D.Kocakavak ve S. Erökten / Pamukkale Üniversitesi Eğitim Fakültesi Dergisi, 53, 1-20, 2021

Çiçek, T. (2011). Illköğretim 6. sınıf fen ve teknoloji dersinde kavram karikatürlerinin ögrenci başarısına, tutumuna ve kalıcılı̆̆a etkisi. Celal Bayar Üniversitesi Fen Bilimleri Enstitüsü, Manisa.

Dabell, J. (2008). Using concept cartoons. Mathematics Teaching Incorporating Micromath, 209, 34-36.

Dalacosta, K., Kamariotaki-Paparrigopoulov, M., Palyvos, J.A. \& Spyrellis, N. (2009). Multimedia application with animated cartoons for teaching science in elemantary education. Computers \& Education (ELSEVIER), 52, 741-748.

Demirci, G. (2013). Eğitimde mizah ve karikatür kullanımının öğrenci başarısı ve motivasyonuna etkisi (Ortaokul 7. sinlf fen ve teknoloji dersi örneği). Gazi Üniversitesi Eğitim Bilimleri Enstitüsü, Ankara.

Ekici, F., Ekici, E. ve Aydın, F. (2007). Utility of concept cartoons in diagnosing and overcoming misconceptions related to photosynthesis. International of Journal of Environmental \& Science Education. 2(4), 111-124.

Eroğlu, N. (2010). 6. sınıf "Maddenin tanecikli yapısı" ünitesindeki kavramların ögretiminde ögrenci ürünü karikatürlerin kullanımı. Sakarya Üniversitesi Fen Bilimleri Enstitüsü, Sakarya.

Evrekli, E. (2010). Fen ve teknoloji ögretiminde zihin haritası ve kavram karikatürü etkinliklerin ögrencilerin akademik başarılarına ve sorgulayıcı öğrenme becerileri algılarına etkisi. Dokuz Eylül Üniversitesi Eğitim Bilimleri Enstitüsü, İzmir.

Evrekli, E.; İnel, D.; Balım, A. (2011). Fen öğretiminde kavram karikatürleri ve zihin haritalarının birlikte kullanımının etkileri üzerine bir araştırma. Necatibey Eğitim Fakültesi Elektronik Fen ve Matematik Ë̆itimi Dergisi (EFMED) , 5(2), 58-85.

Gökharman Kahraman, H. (2013). “Maddenin yapısı ve özellikleri” ünitesinde anoloji kullanımının öğrenci başarısına ve tutumuna etkisi (Çivril örneği). Pamukkale Üniversitesi Eğitim Bilimleri Enstitüsü, Denizli.

Göksu, H.K. (2012). Fen ve teknoloji ögretiminde kavram karikatürlerinin ögrrencilerin akademik başarılarına ve tutumlarına etkisi. Mehmet Akif Ersoy Üniversitesi Fen Bilimleri Enstitüsü, Burdur.

Gölgeli, D. (2012). Düşün-eşleş-paylaş tekniği ile birlikte kullanılan kavram karikatürlerinin öğrencilerin akademik başarıları ile fen ve teknoloji dersine olan 
tutumlarına etkisinin incelenmesi. Erciyes Üniversitesi Eğitim Bilimleri Enstitüsü, Kayseri.

Gölgeli, D. ve Saraçoğlu, S. (2011). Fen ve teknoloji dersi “1ş1k ve ses” ünitesinin öğretiminde kavram karikatürlerinin kullanımının öğrencilerin akademik başarısına etkisi. Sosyal Bilimler Enstitüsü Dergisi, 31(2), 113-124.

İnan, H. ve Kaya, M. (2017). Determining the opinions of physical education teacher candidates about using concept cartoons in education. International Journal of Human Sciences, 4(3), 2666-2676.

Jewett, T. O. (1996). And they is us: Gender issues in the instruction of science. ERIC Document: ED 402202.

Karasar, N. (2009). Bilimsel araştırma yöntemi. Ankara: Nobel Yayın Dağıtım.

Keçeci, G. (2014). Araştırma ve sorgulamaya dayalı fen ögrretiminin öğrencilerin bilimsel süreç becerilerine ve tutumlarına etkisi. Fırat Üniversitesi Eğitim Bilimleri Enstitüsü, Elazığ.

Keogh, B. \& Naylor, S. (1999). Concept cartoons, teaching and learning in science: an evaluatioan. International Journal of Science Education, 21 (4), 431-446.

Korkmaz, H. (2004). Fen ve teknoloji eğitiminde alternatif değerlendirme yaklaşımları. Ankara: Yeryüzü Yayınevi.

Köklükaya, A.N., Yıldırım Güven, E. ve Selvi, M. (2016). The effects of cartoons prepared by pre-service science teachers on academic achievement and anxiety level. Journal of Theory and Practice in Education, 12(2), 427-446.

Köse Özay, E. (2013). Effects of cartoons on students' achievement and attitudes in biology teaching (Endocrine system). Kastamonu Ĕ̈itim Dergisi, 21(3), 931-944.

Meriç, G. (2014). Fen ve teknoloji dersinde kavram karikatürlerinin öğrencilerin kavramsal anlama, motivasyon ve tutum düzeyleri üzerine etkisi. Celal Bayar Üniversitesi Fen Bilimleri Enstitüsü, Manisa.

Milli Eğitim Bakanlığı [MEB] (2006). İlköğretim Fen ve Teknoloji Dersi (6, 7 ve 8. Sinıflar) Öğretim Programı. Ankara: Talim Terbiye Kurulu Başkanlığı.

Naylor, S. \& Keogh, B. (1999). Contructivism in classroom: theory into practice. Journal of Science Teachers Education. 10(2), 93-106. 
Örs, F. (2007). Karikatür ve eğitim. Bilim ve Aklın Aydınlı̆̆ında Eğitim, 84(7), 26-28.

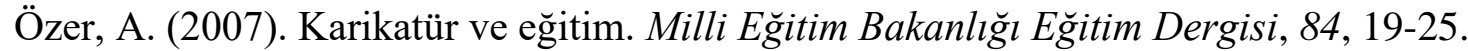

Özün Kılıç, S. (2010). Hayat bilgisi öğretiminde kavram karikatürü yaklaşımının öğrenci başarı ve tutumuna etkisi. Zonguldak Karaelmas Üniversitesi Sosyal Bilimler Enstitüsü, Zonguldak.

Seçkin Kapucu, M. (2014). Fen ve teknoloji dersinde görsel medya kullanımına yönelik fen bilgisi öğretmenlerinin görüşleri. Pegem Ĕ̆itim ve Öğretim Dergisi, 4(2), 75-90.

Steininger, R. (2013, September). How concept cartoons stimulate small-group discourse in upper secondary chemistry classes. European Science Education Research Association (ESERA), Nicosia / Cyprus.

Taş, M. (2013). Karikatür destekli fen öğretimine ilişkin bir araştırma: İlköğretim 6. sınıf yaşamımızdaki elektrik ünitesi örneği. Uludă̆ Üniversitesi Ĕ̆itim Fakültesi Dergisi, 26(2), 473-500.

Taşkın, Ö. (2014). Fen ve teknoloji ögrretiminde kavram karikatürü kullanımının öğrenci başarl ve tutumuna etkisi. Celal Bayar Üniversitesi Fen bilimleri Enstitüsü, Manisa.

Tatar, N. (2006). Illköğretim fen ĕgitiminde araştırmaya dayalı öğrenme yaklaşımının bilimsel süreç becerilerine, akademik başarlya ve tutuma etkisi. Gazi Üniversitesi Eğitim Bilimleri Enstitüsü, Ankara.

TDK, (2015). https://sozluk.gov.tr/?kelime=KAR\%C4\%B0KAT\%20\%C3\%20\%20\%9CR

Erişim tarihi: 08.06.2017.

Tokcan, H. ve Alkan, G. (2013). Sosyal bilgiler öğretiminde kavram karikatürlerinin öğrenci başarısına etkisi. Ahi Evran Üniversitesi Kırşehir Eğitim Fakültesi Dergisi (KEFAD), 14(2), 1-19.

Topçubaşı, T. ve Polat, S. (2014). Sosyal bilgiler öğretiminde kavram karikatürlerinin öğrenci başarısına etkisi. International Journal of New Trends in Arts, Sports \& Science Education 3(2), 48-61.

Uğurel, I. ve Moralı, S. (2006). Karikatürler ve matematik öğretiminde kullanımı. Milli Ĕ̈itim Dergisi, 35(170), 47-66.

Uslu, H. (2007). Eğitimde karikatür. Bilim ve Aklın Aydınlı̆̆ında Ĕgitim Dergisi, 84, 15-18. 
Yaman, H. (2010). Bir öğretim aracı olarak karikatür: Türkçe dilbilgisi üzerine bir araştırma. Kuram ve Uygulamada Ĕgitim Bilimleri, 10(2), 1215-1241.

Y1lmaz, T. (2013). Kavram karikatürleriyle desteklenmiş bilimsel hikayelerin ögrencilerin akademik başarlları, tutumları ve motivasyonları üzerine etkisi. Celal Bayar Üniversitesi Fen Bilimleri Enstitüsü, Manisa.

Yin Yin, K., Wai Bing, K. Yusof, H. \& Zakariya, Z. (2016). An exploratory study on peer learning using concept cartoons. International Journal of Academic Research in Business and Social Sciences, 6(9), 256-264.

Yolcu, H. (2013). Fen öğretiminde kavram karikatürleri tekniğinin yapılandırmacı öğrenme ortamında kullanılmasının ilköğretim 7. sınıf ögrencilerinin başarı, tutum ve mantıksal düşünme yeteneklerine etkisi. Mustafa Kemal Üniversitesi Sosyal Bilimler Enstitüsü, Hatay.

Yong , C. L. \& Kee, C.Z. (2017). Utilizing concept cartoons to diagnose and remediate misconceptions related to photosynthesis among primary school students. In: Karpudewan M., Md Zain A., Chandrasegaran A. (eds), Overcoming Students' Misconceptions in Science (pp. 9-27). 


\title{
Impact of Science Education Enriched with Cartoons on Students' Success and Attitude*
}

\author{
Derya KOCAKAVAK ${ }^{* *} \&$ Seçil ERÖKTEN***
}

· Received: 25.02.2020 · Accepted: 13.12.2020 - Online First: 13.12.2020

\begin{abstract}
This study aims to investigate the impact of science education enriched with cartoons on student success and attitude. The study took a total of 17 weeks, in the spring semester of the 2017-2018 academic year in a secondary school in Denizli, with fifth-grade students consisting of 141 students, 70 students in the experimental group, and 71 students in the control group. The experimental and control groups were randomly determined by purposive sampling. In the study, a semi-experimental pattern with the pretest-final test control group was used. The "Science Achievement Test" developed by the researcher to measure the students' knowledge was used as a data collection tool. The "Science Attitude Scale" developed by Keçeci (2014) was used to measure students' attitudes towards science lessons. In addition, the "Cartoon Supported Lecture Pages and Concept Caricature Worksheets" containing the goals and achievements of the units were prepared by the researcher. Descriptive analysis was performed in the research, and the Mann-Whitney U test was used. As a result of the analysis, it was determined that teaching science supported by cartoons increased students ' academic success but did not significantly change their attitude to the science course.
\end{abstract}

Key Words: Cartoon, academic achievement, attitude

\section{Cited:}

Kocakavak, D. \& Erökten, S. (2021). Impact of science education enriched with cartoons on students' success and attitude. Pamukkale University Journal of Education, 53, 1-20. doi:10.9779.pauefd.694569.

\footnotetext{
* This study was produced from the first author's master thesis.

${ }^{* * *}$ Science Teacher, Denizli, Turkey. ORCID: 0000-0003-0164-6818, deryakocakavak@gmail.com

**** Prof. Dr., Pamukkale University, Faculty of Education, Department Of Science Education, Denizli, Turkey. ORCID: 00000002-3149-5267, erokten@ pau.edu.tr
} 


\section{Introduction}

Science is a discipline that helps us to know and understand the world we live. Science is not only made up of immutable facts. It is also a discipline based on thinking and trial and error (Ministry of National Education, 2006). In order to ensure permanence and effective learning in science education, it is believed that more stimulants should be included in course processing. Audiovisual tools have an important influence on the embodiment of abstract concepts in science. For this reason, visual learning and teaching tools have been emphasized in Science Education (Seçkin Kapucu, 2014). Visual elements are more easily shaped in the brain than reading. Visual elements help students ' attention and notice remains active for a long time.

For this reason, we can say that the use of cartoons in the educational training process, in which visuals are at the forefront, will increase efficiency and permanent learning (Örs, 2007). The word cartoon has come to our language from French. According to the Turkish Language Institution (2015), caricature means a picture that deals with all kinds of issues related to people and the society they live in, such as the environment, hunger, poverty, global warming, and exaggerates these issues, makes you laugh and also makes you think. According to Özer (2007), a caricature is a craft that combines drawings and humor. Cartoons are a visual language in which human emotions and thoughts are expressed with drawings, pictures, and symbols. While presenting the subject in its simplest form, it adds humor and exaggerated drawings into the work (Dalacosta, Kamariotaki-Paparrigopoulov, Polyvos \& Spyrellis, 2009). The cartoon is visual and intriguing. Cartoons are tools that can easily initiate the discussion environment. In education, a caricature is used as a means of visual communication and plays an important role in the learning-teaching process in its humorous aspect (Ayylldı, 2010). The caricature will be a good resource in education, especially in a foreign language, humanities, and science courses (Özer, 2007). In science teaching, individuals can learn by doing and experiencing by using the humorous, creative, and interesting features of the cartoon. Concept teaching can also be provided with the cartoon's characteristics such as humor, creativity, and attractiveness. It also contributes to developing individuals ' skills such as thinking, perceiving, noticing, commenting, criticizing, being open to criticism, and self-criticism. Since it is known that the most permanent learning situation in educational sciences is the activities that they participate in by doing and living, the interpretation of cartoons can be left to students. Permanent learning can be realized (Eroğlu, 2010). According to the educator and cartoonist writer Hakkı Uslu (2007), cartoons enable students to express themselves by developing their critical and creative thinking skills and humorous and aesthetic perspectives while also 
D.Kocakavak \& S. Erökten / Pamukkale University Journal of Education, 53, 1-20, 2021 allowing them to be more sensitive to society's live. Also, students learn while having fun with cartoons so that their attention can also remain active for longer.

Concept caricatures are among the alternative learning-teaching methods due to their visual richness (Ekici, Ekici, \& Aydın, 2007). Concept caricatures are different from other kinds of caricatures. They do not contain exaggeration and humor. Concept caricatures with drawings allow them to be in the caricature group (Uğurel and Moralı, 2006). According to Baysar1 (2007), concept cartoons differ from humorous cartoons. Although concept cartoons contain humorous content, they are similar in structure to the multiple-choice question style. However, unlike multiple-choice questions, there are speech bubbles and visual elements in concept cartoons (Naylor \& Keogh, 1999). According to Dabell (2008), concept cartoons create learning environments by creating mental contradictions in students. When Concept caricatures are applied in the classroom, the student has the opportunity to explain his or her ideas while defending the character in the caricature. The teacher can easily apply concept cartoons to students of all ages, abilities, and levels (Baysar1, 2007). If we briefly summarize the reasons why concept cartoons are used in Science Education (Balım, İnel, Evrekli, \& Kesercioğlu, 2008; Keogh \& Naylor, 1999; Korkmaz, 2004); concept caricatures enable students to research, question, develop different perspectives on the problems they face, be active in the learning process, and communicate effectively.

Affective space and cognitive space occupy a very important place in Science Education (Çepni, 2007). Individuals ' attitudes begin to take shape from the moment they are born. For this reason, students must develop a positive attitude toward science at an early age (Jewett, 1996). Students' ability to develop a positive and meaningful attitude towards science lessons depends on the teacher's moderate approach, encouraging the student to learn by doing and living, and increasing the level of self-efficacy of the students (Gökharman Kahraman, 2013). Suppose a science education can be offered to students that can associate the information they receive with their lives. In that case, it can be ensured that students' attitudes and behaviors towards science lessons increase, and they grow as science-literate individuals in every period of their lives (Tatar, 2006). Students' positive attitudes towards the science course affect their academic achievement, their tendency towards science, and the process of gaining a scientific attitude. (Altınok,2004). The methods and techniques used by science teachers have a very effective and important role in developing a positive attitude towards science by students (Göksu, 2012). One of these techniques is caricatures and concept caricatures. It is believed 
that the use of caricature and concept caricature in science courses will also positively affect students ' attitudes towards science courses.

Since cartoons play an effective role in learning, various cartoons or concept cartoons were used in this study, and the effects of cartoons on students' success and attitude were examined. Based on this, the sub-problems of the research are stated below:

1. "Is there a significant difference between the success scores of the experimental group students receiving cartoon-supported education and the control group students studying in the science education program?"

2. "Is there a significant difference between the attitudes of the experimental group students receiving cartoon-supported education and the control group students studying in line with the science curriculum towards the science course?"

\section{Method}

This study aimed to examine the effect of the use of cartoons in science class on student achievement and attitude. For this purpose, the pretest-posttest control group quasiexperimental design, one of the research designs, is used. The model that is observed under the researcher's control for the variables to determine the cause-effect relationships and the data is produced as a result is called the experimental design (Karasar, 2009). The experimental design with the pre-test-post-test control group, pre-test, and post-test are applied to the experimental and control groups. In quasi-experimental designs, unlike experimental designs, the subjects' selection is not neutral (Balc1, 2001). According to this model, four branches were randomly selected from previously created branches, one of which was an experimental group and a control group. Both groups of students were given the same tests before and after the research. The research pattern used in the research is summarized in Table 1:

Table1. Research Pattern

\begin{tabular}{|c|c|c|c|}
\hline $\begin{array}{l}\text { Name of the } \\
\text { group }\end{array}$ & $\begin{array}{l}\text { Before The } \\
\text { Procedure }\end{array}$ & Procedures & $\begin{array}{l}\text { After } \\
\text { Procedure }\end{array}$ \\
\hline $\begin{array}{l}\text { Experiment } \\
\text { al Group }\end{array}$ & $\begin{array}{l}\text { Science } \\
\text { Achievement }\end{array}$ & Cartoon-supported teaching & $\begin{array}{l}\text { Science } \\
\text { Achievement Test }\end{array}$ \\
\hline $\begin{array}{l}\text { Control } \\
\text { Group }\end{array}$ & $\begin{array}{l}\text { Test Science } \\
\text { Attitude Scale }\end{array}$ & $\begin{array}{l}\text { Teaching methods existing in the } \\
\text { current curriculum }\end{array}$ & $\begin{array}{l}\text { Science Attitude } \\
\text { Scale }\end{array}$ \\
\hline
\end{tabular}




\section{Study Group (Participants)}

The study group consists of 5th-grade students studying at a secondary school affiliated to the Ministry of National Education in Denizli in the Spring Semester of the 2017-2018 academic years. In the study group, there are 141 students, 68 boys, and 73 girls. In the study, two branches as experimental groups and two branches as control groups were randomly selected by purposeful sampling. Information on the study group is given in Table 2:

Table 2. Characteristics of the Study Group

$\begin{array}{ll}\text { Number of Female } & \text { Number of Male Total } \\ \text { Students } & \text { Students }\end{array}$

\begin{tabular}{lccc}
\hline Experimental Group & 40 & 30 & 70 \\
Control Group & 33 & 38 & 71 \\
\hline
\end{tabular}

\section{Measurement (Data Collection) Tools Used in the Study}

\section{Science Achievement Test}

The Science Achievement Test developed by the researcher consists of 32 items, including gapfilling, true-false, short-answer questions, and multiple-choice questions. While preparing for the Science Achievement Test, the 5th-grade science textbook and related literature were examined, and the acquisitions related to the subject areas were determined. Questions have been prepared for these gains. A pilot study on The Science Achievement Test was conducted after taking four experts' opinions, one of whom was an expert in Science education, two of whom were Science teachers, and one of whom was a Turkish teacher. The pilot study was carried out with 100 seventh-grade students in a secondary school affiliated with the Ministry of National Education in Denizli, who had learned the subjects before due to the change in science teaching. After the pilot application, each item's discrimination and difficulty indexes were calculated separately, and final adjustments were made due to the analysis. The KR20 reliability coefficient of the Science Achievement Test was calculated as 0.93 . This value shows that the Science Achievement Test is reliable. The prepared Science Achievement Test was applied to the experimental and control group students as both a pre-test and a post-test.

\section{Science Attitude Scale}


The science Attitude Scale developed by Keçeci (2014) was used in the study. This scale's Cronbach Alpha reliability coefficient, which measures students' attitude towards science courses, was calculated as 0.90 (Keçeci, 2014). The Science Attitude Scale used in the study is a five-point Likert-type scale. Some of the scale statements include positive (20) and some negative (11) statements. The scale consists of 31 items and three factors. These factors were grouped by the scale developer as the interest in the science course, the curiosity towards the science course, and the science course's association with daily life. The scale was administered to the experimental and control group students as both a pre-test and a post-test.

\section{Cartoon-Supported Lecture Papers and Concept Cartoons Worksheets}

Before preparing cartoon-supported lecture papers and concept caricature worksheets to be used as application tools in the study, the gains included in the fifth-grade science course curriculum were identified. Considering these achievements, 48 cartoons supported lecture papers, and concept cartoons worksheets were prepared. While preparing lecture papers with cartoon support, it was aimed for students to understand the subject by having fun and exploring with the cartoon characters' help and the dialogues between them in each unit. While preparing the concept cartoons worksheets, attention has been paid to the fact that the dialogues are short and to the point, including scientific ideas; both misconceptions and alternative thoughts are included in the dialogues. Cartoon characters were used while preparing concept cartoons worksheets. For the validity of the cartoons created by the researcher, the opinions of an expert faculty member in a science, five Science teachers, one Turkish teacher, and one Visual Arts teacher were used. Corrections were made on the cartoons in line with the opinions.

\section{Procedure}

The research was conducted with 141 students studying in 5th grade for 68 lessons, four hours per week. In the research, which lasted 17 weeks, 20 acquisitions, including Matter and Change, Light Propagation, Human and Environment, and Electrical Circuit Elements units in 5 th grade, were considered. In both groups, the lessons were taught by the researcher. Science Achievement Test and Science Attitude Scale were applied as pre-tests before starting the application.

During the study, lessons were taught in the control group aligned with the Fifth Grade Science Curriculum. During the teaching of the lessons, mainly the student textbook was used. Support was received from the question and answer method and from the videos found on the 
Education Information Network (EBA) subject when necessary. Besides, the lessons were reinforced with the activities in the student textbook.

In the study's experimental group, lessons were taught in line with the 5th grade Science Curriculum, while lessons were supported with cartoons. Forty-eight cartoons-supported lectures and worksheets prepared by the researcher for all acquisitions were prepared. The cartoons created by the researcher were distributed to the students in the experimental group one by one, and the cartoons were shown to the classroom through the smartboard. The students read the cartoons, discussed them together, and the students were provided with the information. In this process, the researcher, that is, the teacher guided the students. In the concept cartoons prepared in the form of worksheets, the worksheets were asked to be answered by the students at the beginning of the lesson to determine the students' prior knowledge and misconceptions. After examining the other cartoons by the students, information was given about who answered what to the questions on the worksheet. Students' opinions on the subject were taken, and a discussion environment was created in the classroom. The students explained the reasons for the wrong answers with joint decisions resulting from the discussion, and it was ensured that the students reached the correct answer in line with common decisions. At the end of the lesson, it was ensured that the students took the necessary notes about the lesson by sticking the handed cartoons in their notebooks.

After the application, Science Achievement Test and Science Attitude Scale have applied again as a post-test.

\section{Data analysis}

In the Science Achievement Test consisting of 32 questions used in the study, 1 point for each correct answer, and 0 points for each wrong answer were given. A minimum of 0 and a maximum of 32 points can be obtained from the test. When we applied the Science Achievement Test to our study group, the KR20 reliability coefficient was calculated as 0.634 . As the significance value of the Shapiro-Wilk test was $\mathrm{p}<0.05$ in the study, it was observed that the data did not show normal distribution. For this reason, it has been decided to make nonparametric analyzes. The Mann-Whitney $U$ test was used to compare the difference between achievement scores of two independent groups, the experimental and control groups.

In the research, a minimum of 31 and a maximum of 155 points can be obtained from the Science Attitude Scale developed by Keçeci (2014), which measures students' attitudes towards the science course. High scores from the scale indicate a positive attitude. When we 
applied the Science Attitude Scale to our study group, the Cronbach Alpha reliability coefficient was 0.683 . As the significance value of the Shapiro-Wilk test was $p<0.05$ in the study, it was observed that the data did not show normal distribution. For this reason, it was decided to make nonparametric analyzes. The Mann-Whitney U test was used to compare the difference in attitude scores between two independent groups, the experimental and control groups.

\section{Findings}

The arithmetic means and standard deviation values of the Science Achievement Test and Science Attitude Scale of the experimental and control groups before and after the application are given in Table 3.

When Table 3 is examined, it is seen that the average arithmetic scores of the experimental group students in the achievement test were $X=7.25$ before the application. In contrast, the arithmetic means increased to $X=29.61$ after the application. When the attitude scale pretest scores of the experimental group students are examined, it is seen that the arithmetic means $X=81.27$, and the arithmetic average after the application increased to $\mathrm{X}=$ 81.38. When the achievement test pretest scores of the control group students were examined, it was seen that the arithmetic means $X=7.07$, and the arithmetic means increased to $X=25.76$ after the application. When the attitude scale pretest success scores of the control group students are examined, it is seen that the arithmetic means $X=84.04$; after the application, the arithmetic average decreased to $\mathrm{X}=82.76$.

Table 3. Arithmetic Average and Standard Deviation Values of Applied Achievement Test and Attitude Scale Scores

\begin{tabular}{lcccccccccc}
\hline & & \multicolumn{4}{c}{ Achievement Test } & \multicolumn{3}{c}{ Attitude Scale } \\
\cline { 2 - 10 } & & \multicolumn{2}{c}{ Pretest } & & Posttest & & Pretest & \multicolumn{2}{c}{ Posttest } \\
\hline & $\mathrm{N}$ & $\mathrm{X}$ & Ss & X & Ss & X & Ss & X & Ss \\
Experimental Group & 70 & 7,25 & 2,47 & 29,61 & 1,91 & 81,27 & 8,86 & 81,38 & 6,89 \\
Control Group & 71 & 7,07 & 3,71 & 25,76 & 3,82 & 84,04 & 9,03 & 82,76 & 11,63 \\
\hline
\end{tabular}

Mann-Whitney U test was used to analyze the experimental group's achievement test scores and control group students before the application, and the results are shown in Table 4. 
D.Kocakavak \& S. Erökten / Pamukkale University Journal of Education, 53, 1-20, 2021

9

Table 4. Comparison of Achievement Test Pre-Test Scores of Experimental and Control Group Students

\begin{tabular}{lllllll}
\hline Group & $\mathrm{N}$ & Average Rank & Rank Sum & $\mathrm{U}$ & $\mathrm{z}$ & $\mathrm{p}$ \\
\hline Experimental Group & 70 & 72,51 & 5075,5 & & & \\
Control Group & 71 & 69,51 & 4935,5 & 2379,5 & $-0,438$ & 0,662 \\
\hline
\end{tabular}

According to the Mann-Whitney $U$ test results obtained from Table 4, no statistically significant difference was found between the experimental group students' pre-test success scores and the pre-test success scores of the control group students ( $U=2379,5 ; \mathrm{p}>0,05)$. According to the results, it can be stated that the success levels of the experimental and control group students before the application were equal.

The experimental group's analysis and control group students' attitude scores before the application was made with the Mann-Whitney $U$ test, and the results are shown in Table 5.

Table 5. Comparison of Attitude Scale Pre-Test Scores of Experimental and Control Group Students

\begin{tabular}{lllllll}
\hline Group & $\mathrm{N}$ & Average Rank & Rank Sum & $\mathrm{U}$ & $\mathrm{z}$ & $\mathrm{p}$ \\
\hline $\begin{array}{l}\text { Experimental } \\
\text { Group }\end{array}$ & 70 & 64,5 & 5496 & & & \\
Control Group & 71 & 77,41 & 4515 & 2030 & $-1,879$ & 0,60 \\
\hline
\end{tabular}

According to the Mann-Whitney $U$ test results obtained from Table 5, no statistically significant difference was found between the pre-test attitude scale scores of the experimental group students and the pre-test attitude scale scores of the control group students $(U=2030$; $\mathrm{p}>0,05)$. According to the results, it can be said that the experimental and control group students' attitudes towards the science lesson before the application were equal.

Mann-Whitney U test was conducted to find an answer to the question to the first subproblem of the study, "Is there a significant difference between the achievement scores of the students in the experimental group studying with cartoon support and the students of the control group studying in line with the science curriculum?" The results of this test are presented in Table 6. 
Table 6. Comparison of Post-Test Success Scores of Experimental and Control Group Students

\begin{tabular}{lllllll}
\hline Group & $\mathrm{N}$ & Average Rank & Rank Sum & $\mathrm{U}$ & $\mathrm{z}$ & $\mathrm{p}$ \\
\hline Experimental Group & 70 & 94,89 & 6642 & & & \\
Control Group & 71 & 47,45 & 3369 & 813 & $-6,934$ & 0,00 \\
\hline
\end{tabular}

According to the Mann-Whitney $U$ test results obtained from Table 6, it was determined that there is a statistically significant difference between the success scores of the experimental group students and the control group students in favor of the experimental group (U=813; $\mathrm{p}<0,05)$. According to the results, it was observed that there was a higher increase in the academic achievement of students who were given cartoon-supported science education.

The Mann-Whitney U test was conducted to find an answer to the second sub-problem of the study, "Is there a significant difference between the students' attitudes in the experimental group receiving cartoon-supported education and the control group students studying in the science education program?" The results are presented in Table 7.

Table 7. Comparison of Experimental and Control Group Students' Post-Test Attitude Scores

\begin{tabular}{lllllll}
\hline Group & $\mathrm{N}$ & Average Rank & Rank Sum & $\mathrm{U}$ & $\mathrm{z}$ & $\mathrm{p}$ \\
\hline Experimental Group & 70 & 67,29 & 4710,5 & & & \\
Control Group & 71 & 74,65 & 5300,5 & 2225,5 & $-1,071$ & 0,284 \\
\hline
\end{tabular}

According to the Mann-Whitney $U$ test results obtained from Table 7, no statistically significant difference was detected between the experimental group students' attitude scale scores and the control group students $(U=2225,5 ; p>0,05)$. It is seen that teaching with cartoon support does not make a significant difference in students' attitudes towards science courses.

\section{Discussion}

In today's education system, it is aimed to educate individuals who question, investigate, and produce solutions in a constructivist approach. Many alternative teaching methods can be used in the constructivist education approach. Education with cartoons is one of them. Education with cartoons increases students' interest in the lesson and makes lessons fun. Students can also become individuals who can question, research, and produce solutions in education with cartoons. In this study, students' academic achievement scores and attitudes towards science 
D.Kocakavak \& S. Erökten / Pamukkale University Journal of Education, 53, 1-20, 2021

courses were measured and analyzed in cartoon-supported science education prepared by the Ministry of National Education by the fifth-grade achievements in the Science Program of 2017.

In the first sub-problem of the study, the difference between the experimental and control group students' achievement scores in the science course was examined. No significant difference was found between the pre-test scores of the experimental and control groups of the achievement test applied according to the study's findings. In this case, we can say that both groups' success levels are equal before the application. On the other hand, a significant difference was found in the post-test success scores in favor of the experimental group. It suggests that cartoon-supported science education is effective in increasing the academic success of fifth-grade students. The main reason is that cartoon-supported science education enables students to participate more actively in the lesson by enabling classroom discussion. The experimental group students could reach the correct information through trial and error in the discussion environment. Students could synthesize and use the scientific knowledge they had acquired up to that time to think critically and solve problems during the discussion process. Also, with the help of cartoons, the experimental group students could adapt the information to daily life more. However, the control group students reached result-oriented information only by observing the activities in the textbooks. Therefore, students in the control group are thought to be more passive in critical thinking. Students who reinforced their learning with critical thinking in cartoon-supported education were more successful. Another factor in students' academic success in the experimental group where cartoon-supported science education is applied is cartoons' humorous and visual richness. According to Örs (2007), visual elements that attract attention attract more students and facilitate permanent learning. Education became more interesting by using the cartoons' visual and humorous aspects in the experimental group was an important factor in increasing academic success.

In parallel with the findings obtained in the current study, studies have concluded that students' academic achievements in cartoon-supported science education are positively affected. In their studies with middle school students, Dalacosto, Kamariotaki-Paparrigopoulov, Palyvos and Spyrellis (2009), Evrekli (2010); Eroğlu (2010), Chin and Teou (2010), Gölgeli and Saraçoğlu, (2011), Gölgeli, (2012), Çetin (2012), Taş (2013), Demirci (2013), Yolcu (2013), Yılmaz (2013), Taşkın (2014), Yİn Yin, Wai Bing, Yusof and Zakariya (2016), Ayhan (2017) concluded that the use of cartoons positively increased the academic achievement in the science course. Akengin and İbrahimoğlu (2010), Yaman (2010), Akkaya (2011), Tokcan and 
Alkan (2013), Topçubaşı and Polat (2014) found that the use of cartoons in their lessons increased student success in their studies with secondary school students in various branches. Özün Kılıç (2010) and Young and Kee (2017) concluded in their studies with primary school students that the use of cartoons in lessons increased student success. Ayy1ldız (2010) and Köse Özay (2013) observed in their studies with high school students that there was a significant positive difference between the use of cartoons in lessons and their academic achievement. In their studies with teachers and teacher candidates on various branches, Keogh and Naylor (1999), Köklükaya, Yıldırım Güven and Selvi (2016), Steininger (2013), and İnan and Kaya (2017) concluded that the use of cartoons increases the success of both students and teachers. Ayhan (2017) examined the effects of concept cartoons on sixth-grade students' success level in the force and motion unit. In the study, pre-test and post-test, consisting of multiple-choice questions, were applied to the groups. As a result of the study, a significant difference was found in the success scores in favor of the experimental group in which lessons were taught with concept cartoons. Dalacosta, Kamariotaki-Paparrigopoulov, Palyvos, and Spyrellis (2009) aimed to identify and evaluate the effect of animated cartoons on primary school students' learning of scientific subjects in their study. A study conducted with 179 students concluded that the use of cartoons increases learning even in concepts where students' misconceptions are high. There are also studies with different results in terms of academic success. For example, in Göksu's thesis (2012), it was found that the use of concept cartoons did not make a significant difference between the post-test success scores of the experimental and control groups.

In the second sub-problem of the study, the difference between the experimental and control group students' attitude scores towards the science course was examined. No significant difference was found between the post-test attitude scores of the experimental and control groups. Their lives limit individuals' ability to have attitudes. Besides, an individual must have a mind map about developing an attitude to an event or concept (Gökharman Kahraman, 2013). According to the description, it is expected that there will be no significant difference between the attitude scores of the pre-application experimental and the control group. After the study, it was also found that there was no significant difference between the experimental and the control group's final Test attitude scores. We can say that cartoon-supported science education cannot significantly change attitudes because attitudes are formed in a certain process. It is also thought that the change of attitudes is difficult, and even if the change occurs, the fact that it is not immediately observed in the behavioral or affective components is another factor. Karasar (2009) statement that the attitudes of individuals will not easily change supports this idea. 
D.Kocakavak \& S. Erökten / Pamukkale University Journal of Education, 53, 1-20, 2021

In parallel with the findings obtained in the current study, some studies conclude that cartoon-supported Science Education does not make a significant difference in students ' attitudes (Baysarı2007; Evrekli, İnel, Balım 2011; Çiçek, 2011; Gölgeli, 2012; Yılmaz, 2013). Some studies have come to different conclusions in terms of attitude. For example, Meriç's thesis (2014) investigated the effect of concept caricature on student attitude. As a result of Meric's study, it was observed that the final Test attitude scores, in which a concept caricature was used in the experimental group, made a significant difference.

\section{Conclusion}

According to the results of the achievement test and attitude scale conducted to determine the effect of cartoon enriched science application on students, it can be said that science education enriched with cartoons can achieve a better understanding of the lesson and more permanent learning. Still, it does not make a significant difference in attitude towards the lesson. As a result of this research, it can be said that cartoon-supported science teaching has a positive effect on students ' science course success in parallel with the research results contained in the literature in increasing student success. According to another result of this research, it can be said that cartoon-supported science teaching does not affect increasing student attitude in parallel with some research results in the literature.

In this part of the study, the following recommendations were made by the researcher, taking into account the limitations of the research:

1. The research was conducted with fifth-grade students. Cartoon-supported science education applications can also be made with different grade levels.

2. In the study, cartoon-supported science education was limited to 17 weeks. The application time should be taken into account in the studies to be carried out.

3. Apart from the science course, cartoon-supported education can be used in different disciplines.

4. In cartoon-supported training, subjects related to daily life that can attract students ' attention, evoke a sense of curiosity, and lead them to question can be used as introductory activities to the lesson.

5. In this study, cartoon-supported education was limited to the subjects of Matter and Change, Light Spread, Human and Environment, and Electrical Circuit Elements. Applications can also be made in different science subjects. 
6. Using instructions that determine the roles of teachers and students in cartoonsupported activities, the teaching process can be used more effectively and efficiently.

7. It should be ensured that teacher candidates gain experience in the cartoonsupported education process applications.

8. In the cartoon-supported education process, small group discussions should be taken into account for students to see different perspectives, generate more ideas, and participate more in the process.

9. With the support of technology, these cartoons can be made interactive.

Ethical Approval: This study was produced from the master's thesis of the first author.

Conflict Interest: There is no conflict of interest.

Authors' Contributions: The first author created the theoretical framework, data analysis, findings, conclusion, and discussion. The second author contributed to creating the theoretical framework, findings, conclusion and discussion, and recommendations. 


\section{References}

Akengin, H. ve İbrahimoğlu, Z. (2010). Sosyal bilgiler dersinde karikatür kullanımının öğrencilerin akademik başarısına ve derse ilişskin görüşlerine etkisi. Ondokuz Mayıs University Journal of Education Faculty, 29(2), 1-19.

Akkaya, A. (2011). Karikatürlerle dil bilgisi ögrretimi. Selcuk University Institute of Educational Sciences, Konya.

Altınok, H. (2004). İşbirlikli Öğrenme, Kavram Haritalama, Fen Başarısı, Strateji Kullanımı ve Tutum. Dokuz Eylul University Institute of Educational Sciences, İzmir.

Ayhan, H. (2017). Ortaokul 6. sinıf kuvvet ve hareket ünitesinde kullanılan kavram karikatürlerinin öğrencilerin akademik başarılarına ve fen ögrrenmeye yönelik motivasyonlarına etkisi. Gazi University Institute of Educational Sciences, Ankara.

Ayyıldız, N. (2010). Coğrafya öğretiminde karikatür materyali kullanımının öğrenci başarısına etkisi. Marmara University Institute of Educational Sciences, İstanbul.

Balc1, A. (2001). Sosyal bilimlerde araştırma yöntem, teknik ve ilkeler. Ankara: Pegama Publishing

Balım, A., İnel, D., Evrekli, E. ve Kesercioğlu, T. (2008). The use of concept cartoons in constructive science and technology education: "The examples about the subject of presssure”. XIII. IOSTE Symposium, The Use of Science and Technology Education for Peace and Sustainable Development, Kuşadası/Turkey.

Baysarı, E. (2007). Illköğretim düzeyinde 5. sinıffen ve teknoloji dersi canlılar ve hayat ünitesi öğretiminde kavram karikatürü kullanımının öğrenci başarısına, fen tutumuna ve kavram yanılgilarinın giderilmesine olan etkisi. Dokuz Eylul University Institute of Educational Sciences, İzmir.

Chin, C. \& Teou, L-Y. (2009). Using concept cartoons in formative assessment: Scaffolding students' argumentation. International Journal of Science Education. 31(10), 13071332.

Çepni, S. (Ed.) (2007). Kuramdan uygulamaya fen ve teknoloji öğretimi. Ankara: Pegama Publishing.

Çetin, E. (2012). Karikatürler ile zenginleştirilmiş fen ve teknoloji dersinin ögrrenci başarısı ve tutumlarl üzerine etkisi. Selcuk University Institute of Educational Sciences, Konya. 
Çiçek, T. (2011). İlköğretim 6. sinıffen ve teknoloji dersinde kavram karikatürlerinin öğrenci başarısına, tutumuna ve kalıcılı̆̆a etkisi. Celal Bayar University Institute of Science and Technology, Manisa.

Dabell, J. (2008). Using concept cartoons. Mathematics Teaching Incorporating Micromath, 209, 34-36.

Dalacosta, K., Kamariotaki-Paparrigopoulov, M., Palyvos, J.A. \& Spyrellis, N. (2009). Multimedia application with animated cartoons for teaching science in elemantary education. Computers \& Education (ELSEVIER), 52, 741-748.

Demirci, G. (2013). Eğitimde mizah ve karikatür kullanımının öğrenci başarısı ve motivasyonuna etkisi (Ortaokul 7. sınıf fen ve teknoloji dersi örneği). Gazi University Institute of Educational Sciences, Ankara.

Ekici, F., Ekici, E. ve Aydın, F. (2007). Utility of concept cartoons in diagnosing and overcoming misconceptions related to photosynthesis. International of Journal of Environmental \& Science Education. 2(4), 111-124.

Eroğlu, N. (2010). 6. sınıf “Maddenin tanecikli yapısı” ünitesindeki kavramların ögretiminde öğrenci ürünü karikatürlerin kullanımı. Sakarya University Institute of Science and Technology, Sakarya.

Evrekli, E. (2010). Fen ve teknoloji ögrretiminde zihin haritası ve kavram karikatürü etkinliklerin öğrencilerin akademik başarılarına ve sorgulayıcı öğrenme becerileri algılarına etkisi. Dokuz Eylul University Institute of Educational Sciences, İzmir.

Evrekli, E.; İnel, D.; Balım, A. (2011). Fen öğretiminde kavram karikatürleri ve zihin haritalarının birlikte kullanımının etkileri üzerine bir araştırma. Necatibey Faculty of Education Electronic Journal of Science and Mathematics Education (EFMED) , 5(2), $58-85$.

Gökharman Kahraman, H. (2013). "Maddenin yapısı ve özellikleri” ünitesinde anoloji kullanımının öğrenci başarısına ve tutumuna etkisi (Çivril örneği). Pamukkale University Institute of Educational Sciences, Denizli.

Göksu, H.K. (2012). Fen ve teknoloji öğretiminde kavram karikatürlerinin öğrencilerin akademik başarılarına ve tutumlarına etkisi. Mehmet Akif Ersoy University Institute of Science and Technology, Burdur. 
D.Kocakavak \& S. Erökten / Pamukkale University Journal of Education, 53, 1-20, $2021 \quad 17$

Gölgeli, D. (2012). Düşün-eşleş-paylaş tekniği ile birlikte kullanılan kavram karikatürlerinin ögrencilerin akademik başarllart ile fen ve teknoloji dersine olan tutumlarına etkisinin incelenmesi. Erciyes University Institute of Educational Sciences, Kayseri.

Gölgeli, D. ve Saraçoğlu, S. (2011). Fen ve teknoloji dersi “1şık ve ses” ünitesinin öğretiminde kavram karikatürlerinin kullanımının öğrencilerin akademik başarısına etkisi. Journal of the Institute of Social Sciences, 31(2), 113-124.

İnan, H. ve Kaya, M. (2017). Determining the opinions of physical education teacher candidates about using concept cartoons in education. International Journal of Human Sciences, 4(3), 2666-2676.

Jewett, T. O. (1996). And they is us: Gender issues in the instruction of science. ERIC Document: ED 402202.

Karasar, N. (2009). Bilimsel araştırma yöntemi. Ankara: Nobel Publication\&Distribution.

Keçeci, G. (2014). Araştırma ve sorgulamaya dayalı fen öğretiminin öğrencilerin bilimsel süreç becerilerine ve tutumlarına etkisi. Firat University Institute of Educational Sciences, Elazı $\breve{g}$.

Keogh, B. \& Naylor, S. (1999). Concept cartoons, teaching and learning in science: an evaluatioan. International Journal of Science Education, 21 (4), 431-446.

Korkmaz, H. (2004). Fen ve teknoloji ĕgitiminde alternatif değerlendirme yaklaşımları. Ankara: Yeryüzü Publishing House.

Köklükaya, A.N., Yıldırım Güven, E. ve Selvi, M. (2016). The effects of cartoons prepared by pre-service science teachers on academic achievement and anxiety level. Journal of Theory and Practice in Education, 12(2), 427-446.

Köse Özay, E. (2013). Effects of cartoons on students' achievement and attitudes in biology teaching (Endocrine system). Kastamonu Journal of Education, 21(3), 931-944.

Meriç, G. (2014). Fen ve teknoloji dersinde kavram karikatürlerinin öğrencilerin kavramsal anlama, motivasyon ve tutum düzeyleri üzerine etkisi. Celal Bayar University Institute of Science and Technology, Manisa.

Milli Eğitim Bakanlı̆̆ [MEB] (2006). İlköğretim Fen ve Teknoloji Dersi (6, 7 ve 8. Sinıflar) Öğretim Programı. Ankara: Board of Education. 
Naylor, S. \& Keogh, B. (1999). Contructivism in classroom: theory into practice. Journal of Science Teachers Education. 10(2), 93-106.

Örs, F. (2007). Karikatür ve eğitim. Bilim ve Aklın Aydınlı̆̆ında Ĕ̆itim, 84(7), 26-28.

Özer, A. (2007). Karikatür ve eğitim. Ministry of Education Journal of Education, 84, 19-25.

Özün Kılıç, S. (2010). Hayat bilgisi öğretiminde kavram karikatürü yaklaşımının öğrenci başarl ve tutumuna etkisi. Zonguldak Karaelmas University Institute of Social Sciences, Zonguldak.

Seçkin Kapucu, M. (2014). Fen ve teknoloji dersinde görsel medya kullanımına yönelik fen bilgisi öğretmenlerinin görüşleri. Pegem Education and Training Journal, 4(2), 75-90.

Steininger, R. (2013, September). How concept cartoons stimulate small-group discourse in upper secondary chemistry classes. European Science Education Research Association (ESERA), Nicosia / Cyprus.

Taş, M. (2013). Karikatür destekli fen öğretimine ilişkin bir araştırma: İlköğretim 6. sınıf yaşamımızdaki elektrik ünitesi örneği. Journal of Uludağ University Education Faculty, 26(2), 473-500.

Taşkın, Ö. (2014). Fen ve teknoloji ögrretiminde kavram karikatürü kullanımının öğrenci başarı ve tutumuna etkisi. Celal Bayar University Institute of Science, Manisa.

Tatar, N. (2006). İlköğretim fen ĕgitiminde araştırmaya dayalı öğrenme yaklaşımının bilimsel süreç becerilerine, akademik başartya ve tutuma etkisi. Gazi University Institute of Educational Sciences, Ankara.

TDK, (2015). https://sozluk.gov.tr/?kelime=KAR\%C4\%B0KAT\%20\%C3\%20\%20\%9CR

Date of access: 08.06.2017.

Tokcan, H. ve Alkan, G. (2013). Sosyal bilgiler öğretiminde kavram karikatürlerinin öğrenci başarısına etkisi. Ahi Evran University Journal of Kırşehir Education Faculty (KEFAD), 14(2), 1-19.

Topçubaşı, T. ve Polat, S. (2014). Sosyal bilgiler öğretiminde kavram karikatürlerinin öğrenci başarısına etkisi. International Journal of New Trends in Arts, Sports \& Science Education 3(2), 48-61.

Uğurel, I. ve Moralı, S. (2006). Karikatürler ve matematik öğretiminde kullanımı. Journal of National Education, 35(170), 47-66. 
D.Kocakavak \& S. Erökten / Pamukkale University Journal of Education, 53, 1-20, 2021

Uslu, H. (2007). Eğitimde karikatür. Bilim ve Aklın Aydınlı̆̆ında Eğitim Dergisi (Education Journal in the Light of Science and Mind), 84, 15-18.

Yaman, H. (2010). Bir öğretim aracı olarak karikatür: Türkçe dilbilgisi üzerine bir araştırma. Kuram ve Uygulamada Ĕ̈itim Bilimleri, 10(2), 1215-1241.

Yılmaz, T. (2013). Kavram karikatürleriyle desteklenmiş bilimsel hikayelerin öğrencilerin akademik başarıları, tutumları ve motivasyonları üzerine etkisi. Celal Bayar University Institute of Science and Technology, Manisa.

Yin Yin, K., Wai Bing, K. Yusof, H. \& Zakariya, Z. (2016). An exploratory study on peer learning using concept cartoons. International Journal of Academic Research in Business and Social Sciences, 6(9), 256-264.

Yolcu, H. (2013). Fen öğretiminde kavram karikatürleri tekniğinin yapılandırmacı öğrenme ortamında kullanılmasının ilköğretim 7. sınıf ögrrencilerinin başarı, tutum ve mantıksal düşünme yeteneklerine etkisi. Mustafa Kemal University Institute of Social Sciences, Hatay.

Yong , C. L. \& Kee, C.Z. (2017). Utilizing concept cartoons to diagnose and remediate misconceptions related to photosynthesis among primary school students. In: Karpudewan M., Md Zain A., Chandrasegaran A. (eds), Overcoming Students' Misconceptions in Science (pp. 9-27). 